\title{
ANÁLISE QUALI-QUANTITATIVA DA ARBORIZAÇÃO URBANA DO MUNICÍPIO DE SÃO JOÃO EVANGELISTA-MG
}

\author{
Ildeane Moreira Brandão"; Leilane Bárbara Gomes ${ }^{1}$; Nayane Cristine Amselmo dos Reis \\ Silva'; Ana Carolina Ferraro ${ }^{2}$; Aderlan Gomes da Silva ${ }^{3}$; Fabrício Gomes Gonçalves ${ }^{4}$
}

(recebido em 06.05.2011 e aceito para publicação em 15.12.2011)

\section{RESUMO}

A arborização é um importante componente na paisagem urbana, no entanto, quando feito sem planejamento na implantação e manejo, e quando realizado por pessoal inapto pode gerar conflitos e tornar-se onerosa. $O$ objetivo do presente trabalho foi realizar uma análise quali-quantitativa arbórea da cidade de São João Evangelista-MG, catalogando as espécies existentes no município através do levantamento das condições fitossanitárias e físicas e evidenciar os problemas ocasionados em consequência da ausência de planejamento na implantação das árvores. O tipo de inventário adotado foi inventário total, sendo realizado o levantamento de $100 \%$ dos indivíduos existentes dentro do perímetro urbano do município. Encontrou-se 814 indivíduos pertencentes a 46 espécies. Os resultados indicaram uma maior concentração de indivíduos de poucas espécies sendo que o maior número de árvores encontradas foi da espécie exótica Licania tomentosa representando 61,30\% das espécies levantadas e composta maciçamente por árvores adultas.

Palavras-chave: Arborização urbana; Inventário arbóreo; Licania tomentosa.

\footnotetext{
1. Tecnóloga em Silvicultura, Instituto Federal de Educação Ciência e Tecnologia de Minas Gerais Campus São João Evangelista, São João Evangelista, MG. deanemoreira@hotmail.com; leilanybarbara@hotmail.com; nayaneanselmo@yahoo.com.br.

2. Engenheira Florestal, Professora do Instituto Federal de Educação Ciência e Tecnologia de Minas Gerais - Campus São João Evangelista, São João Evangelista, MG. ana.ferraro@ifmg.edu.br.

${ }^{3}$. Engenheiro Florestal, Professor Doutor do Instituto Federal de Educação Ciência e Tecnologia de Minas Gerais - Campus São João Evangelista, São João Evangelista, MG. aderlan.silva@ifmg.edu.br.

4. Engenheiro Florestal, Professor Msc. Universidade Federal do Espírito Santo, Alegre-ES. fabriciogomes@ibest.com.br.
}

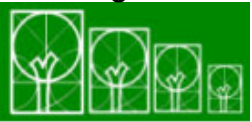

$\mathbf{S} \cdot \mathbf{B} \cdot \mathbf{A} \cdot \mathbf{U}$ Soc. Bras. de Arborização Urbana 


\section{QUALITATIVE AND QUANTITATIVE ANALYSIS OF THE URBAN FORESTRY IN THE CITY OF SÃO JOÃO EVANGELISTA-MG}

\section{ABSTRACT}

The trees are an important component in the urban landscape, however, when implanted without a well planned deployment and management, and when performed by unqualified personnel, it can cause conflicts and become expensive. This study aimed to perform a quali-quantitative analysis of the urban forest in São João Evangelista city in Minas Gerais State, recording the species in the municipality through a plant health and physical conditions survey and to highlight the problems resulted by lack of planning in trees deployment. The survey analyzed all trees individuals found within the urban perimeter. It was found 814 individuals of 46 species. The results indicated a greater concentration of few species with Licania tomentosa representing $61.30 \%$ of the surveyed species and a landscape composed overwhelmingly by mature trees.

Keywords: Urban forestry; Tree inventory; Licania tomentosa.

\section{INTRODUÇÃO}

Segundo o Censo 2010, no Brasil $84,36 \%$ da população reside em áreas urbanas (IBGE, 2011). Um dos fatores que afetam a qualidade de vida do homem urbano é a condição ambiental das cidades que, segundo Milano (1987), normalmente são muito influenciadas pelas características dos materiais e formas existentes, bem como pelas atividades desenvolvidas nos centros urbanos.

A Organização Mundial de Saúde (OMS) define saúde não apenas como a ausência de doença, mas como a situação de perfeito bem-estar físico, mental e social (BUSS, 2000).

Para que uma cidade se torne saudável, salienta-se a construção de um ambiente físico limpo e saudável e um ecossistema estável e sustentável (ADRIANO et al., 2000). 
Entre os benefícios propiciados pela arborização destaca-se melhoria na qualidade do ar, redução da amplitude térmica, bem estar psicológico ao homem tornando o ambiente mais atrativo, sombra para pedestres e veículos, redução da poluição sonora, proteção e direcionamento do vento, abrigo para pássaros e equilíbrio estético que ameniza a diferença entre a escala humana e outros componentes da cidade.

As primeiras ruas a serem arborizadas com plantio de árvores foram as de Paris, no ano de 1660 , com os objetivos de embelezar a cidade e proteger os movimentos militares, além de servirem como material para barricadas. Desde essa época, então, as árvores têm sido utilizadas em todas as cidades segundo Takahashi (1992), citado por Gonçalves et al. (2004).

Segundo Milano (1994), a arborização no Brasil é uma atividade relativamente nova e tem sido realizada com raras exceções, sem planejamento. Neste contexto, a arborização de ruas requer, para a efetivação dos benefícios esperados, que seja adequadamente planejada e mantida de forma sustentável.

Segundo Santos (2008), as espécies utilizadas na arborização de ruas devem ser muito bem selecionadas devido às condições adversas a que são submetidas. Segundo o mesmo autor, em condições de mata natural, fatores como porte, tipo e diâmetro da copa, hábito de crescimento das raízes e altura da primeira bifurcação se comportam diferentemente em comparação ao meio urbano. Na seleção de espécies devem-se considerar, também, fatores como adaptabilidade, sobrevivência e desenvolvimento no local de plantio.

Para a escolha da espécie adequada, a árvore deve conter certas características como: estar adaptada ao clima do local destinado, ser espécie nativa da vegetação local, ter raízes profundas, possuir porte adequado ao espaço disponível, apresentar tronco único e copa bem definida, dar frutos pequenos e silvestres, dar flores pequenas, pouco suculentas, e com cores vivas, ter folhas preferencialmente pequenas e não coriáceas, ter desenvolvimento rápido, apresentar baixa toxidade e não possuir espinhos ou acúleos.

A arborização não planejada e realizada por pessoal inapto pode ter influência negativa direta em alguns elementos da organização urbana como redes de distribuição de energia elétrica e telefônica e sistemas de abastecimento de água e esgoto (MENESES et al., 2003). Portanto, este plantio deve seguir critérios para que as espécies escolhidas possam cumprir seu papel, interferindo o menos possível na vida urbana (OLIVEIRA et al., 2009).

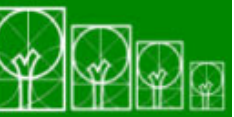

$\mathbf{S} \cdot \mathbf{B} \cdot \mathbf{A} \cdot \mathbf{U}$ Soc. Bras. de Arborização Urbana

REVSBAU, Piracicaba - SP, v.6, n.4, p.158-174, 2011 
Segundo Santos e Teixeira (2001), o uso da vegetação, ao longo da malha urbana, constitui uma forma de auxiliar na preservação do equilíbrio biológico.

Segundo Minhoto; Monteiro e Fisch (2009), para a obtenção dos benefícios da arborização, torna-se necessário um planejamento prévio e para a arborização já implantada, um sistema de monitoramento que permita avaliar as características das árvores e seus respectivos locais de plantio.

Este trabalho teve como objetivo realizar um inventário urbanístico das árvores do município de São João Evangelista, visando um planejamento posterior para a cidade. Desta forma se fez necessário realizar uma análise quali-quantitativa arbórea, catalogando as espécies existentes no município, com um levantamento das condições fitossanitárias e físicas das mesmas para evidenciar os problemas ocasionados em consequência da ausência de planejamento na implantação das árvores.

\section{MATERIAIS E MÉTODOS}

Esta pesquisa de campo é de caráter quali-quantitativo sendo o presente estudo realizado no município de São João Evangelista, localizado na região Centro Nordeste do Estado de Minas Gerais, com uma área de 478,82 km² $^{2}$ e população aproximada de 16.254 habitantes (IBGE, 2010), Índice de Desenvolvimento Humano Médio (IDH) de 0,683 (PNUD, 2000) e Produto Interno Bruto (PIB) per capita de $\mathrm{R} \$ 2.868,97$ (IBGE, 2005).

Localiza-se à aproximadamente $689 \mathrm{~m}$ de altitude média do nível mar, nas coordenadas $18^{\circ} 32^{\prime} 52^{\prime \prime} \mathrm{S}$ e $42^{\circ} 45^{\prime} 46^{\prime \prime} \mathrm{O}$ e possui clima do tipo tropical de altitude Cwa.

Segundo Milano e Dalcin (2000), o tipo de inventário utilizado deve ser em função dos objetivos especificamente definidos, fundamentados em diferentes metodologias e graus de precisão.

Os dados foram coletados no período de março a abril de 2009. O tipo de inventário adotado foi inventário total, sendo realizado o levantamento de $100 \%$ dos indivíduos existentes dentro do perímetro urbano do município. Foram considerados os indivíduos localizados em canteiros, vias públicas, praças e outras áreas verdes. Apenas foram excluídos os pertencentes às áreas residenciais e privadas.

Os indivíduos que apresentavam bifurcação abaixo de 1,30m foram considerados como sendo mais de um indivíduo, segundo recomendações de Soares; Neto e Souza

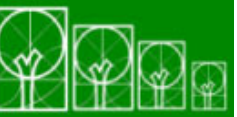

$\mathbf{S} \cdot \mathbf{B} \cdot \mathbf{A} \cdot \mathbf{U}$ Soc. Bras. de Arborização Urbana

REVSBAU, Piracicaba - SP, v.6, n.4, p.158-174, 2011 
(2007). Utilizou-se para a coleta de dados um formulário previamente elaborado adaptado de Silva; Paiva e Gonçalves (2007). Para um melhor desenvolvimento e organização do inventário foi utilizado um mapa atualizado de todas as ruas e praças, fornecido pelo Instituto Brasileiro de Geografia e Estatística (IBGE) atuante no município. Utilizou-se o software MICROSOFT EXCEL ${ }^{\circledR}$ (2000) para tabulação dos dados. No presente estudo, foram adotados as variáveis: fitossanidade, problema de raiz, largura do passeio, conflito com a fiação, circunferência de ocupação (CAP), diâmetro de copa, altura total, altura da primeira bifurcação e idade, conforme Silva; Paiva e Gonçalves (2007), apresentadas na Tabela 1.

Tabela 1. Classe de variáveis analisadas no Inventário Arbóreo do município de São João Evangelista-MG

Table 1. Class of analized variables in the Inventory of the city of São João Evangelista-MG

\begin{tabular}{|c|c|c|c|c|}
\hline \multirow{2}{*}{ Variável } & \multicolumn{4}{|c|}{ Classe } \\
\hline & 0 & 1 & 2 & 3 \\
\hline Fitossanidade & Morta & Ruim & Regular & Boa \\
\hline $\begin{array}{c}\text { Problema de } \\
\text { raiz }\end{array}$ & $\begin{array}{c}\text { Não apresenta } \\
\text { raiz exposta }\end{array}$ & Aponta as raízes & $\begin{array}{l}\text { Quebra o } \\
\text { passeio }\end{array}$ & $\begin{array}{c}\text { Destrói o } \\
\text { passeio }\end{array}$ \\
\hline $\begin{array}{c}\text { Largura do } \\
\text { passeio }\end{array}$ & Não tem passeio & $0-1,5 \mathrm{~m}$ & $1,5-3,0 \mathrm{~m}$ & $>3,0 \mathrm{~m}$ \\
\hline $\begin{array}{l}\text { Conflito com a } \\
\text { fiação }\end{array}$ & Não apresenta & Abaixo & Meio & Acima \\
\hline $\begin{array}{l}\text { Circunferência } \\
\text { de ocupação }\end{array}$ & $<15 \mathrm{~cm}$ & $15,0-30,0 \mathrm{~cm}$ & $30,1-45,0 \mathrm{~cm}$ & $>45,0 \mathrm{~cm}$ \\
\hline $\begin{array}{c}\text { Diâmetro de } \\
\text { copa }\end{array}$ & $<4,0 \mathrm{~m}$ & $4,1-7,0 \mathrm{~m}$ & $7,1-10,0 \mathrm{~m}$ & $>10,0 \mathrm{~m}$ \\
\hline Altura total & $<5,0 m$ & $5,0-10,0 \mathrm{~m}$ & $10,1-15,0 m$ & $>15,0 \mathrm{~m}$ \\
\hline $\begin{array}{c}\text { Altura da } \\
\text { primeira } \\
\text { bifurcação }\end{array}$ & $<1,0 m$ & $1,0-1,5 \mathrm{~m}$ & $1,6-2,0 \mathrm{~m}$ & $>2,0 \mathrm{~m}$ \\
\hline Idade & Muda & Jovem & Adulta & Velha \\
\hline
\end{tabular}

Fonte: Silva; Paiva; Gonçalves (2007), com modificações. 
Segundo Silva, Paiva e Gonçalves (2007), a condição das árvores urbanas, geralmente é avaliada por meio de um parâmetro denominado fitossanidade, o qual se refere às condições de sanidade dos espécimes avaliados visualmente, com base no seu aspecto físico geral. Esse parâmetro está entre os mais importantes em inventários florestais urbanos, pois através dele pode ser conhecido o "estado de saúde" da arborização.

Destacam-se as seguintes classes de fitossanidade:

$3=$ árvore boa: 0 indivíduo apresenta-se vigoroso, sem sinais de pragas, doenças ou danos mecânicos e apresenta a forma característica da espécie, não requerendo trabalhos de correção.

2= árvore regular: apresenta condição e vigor médios para determinado local, podendo apresentar pequenos danos físicos, pequenos problemas de pragas e doenças, ou ainda necessidade de poda corretiva.

$1=$ árvore ruim: apresenta estágio geral de declínio e pode apresentar severos danos de pragas, doenças ou físicos, e embora não apresente morte iminente, pode requerer muito trabalho para sua recuperação.

$0=$ árvore morta ou que, devido a danos físicos, de pragas ou de doenças, aparenta morte iminente.

Foi analisada também a diversidade arbórea, segundo Scolforo e Melo (2006), utilizando-se o Quociente de Mistura de Jentsch (QM) representado pela fórmula:

$\mathrm{QM}=\mathrm{S} / \mathrm{N}$

Onde:

QM = Quociente de Mistura de Jentsch;

$\mathrm{S}=$ número total de espécies, e;

$\mathrm{N}=$ número de indivíduos.

\section{RESULTADOS E DISCUSSÃO}

A Tabela 2 apresenta a listagem das espécies recenseadas no município de São João Evangelista e o número de indivíduos encontrados: 
Tabela 2. Lista de espécies encontradas no município de São João Evangelista-MG, 2009 Table 2. List of species found in the city of São João Evangelista-MG, 2009

\begin{tabular}{|c|c|c|}
\hline Espécie & Família & $\begin{array}{c}\text { Número } \\
\text { de } \\
\text { Indivíduos }\end{array}$ \\
\hline Araucária angustifólia (Bertol.) Kuntze & Araucariaceae & 1 \\
\hline Bauhinia spp. & Caesalpiniaceae & 30 \\
\hline Caesalpinia leiostachya (Benth.) Ducke & Caesalpiniaceae & 6 \\
\hline Caesalpinia peltophoroides Benth. & Caesalpiniaceae & 33 \\
\hline Cassia leiandra Benth. & Caesalpiniaceae & 2 \\
\hline Cedrela fissilis Vell. & Meliaceae & 6 \\
\hline Chorisia speciosa A. St-Hil. & Bombacaceae & 1 \\
\hline Copaifera longsdorffii Desf. & Caesalpiniaceae & 3 \\
\hline Cupressus & Cupressaceae & 2 \\
\hline Dalbergia nigra (Vell.) Allemão ex Benth. & Fabaceae & 5 \\
\hline Dypterix alata Vogel. & Fabaceae & 6 \\
\hline Ficus spp. & Moraceae & 49 \\
\hline $\begin{array}{l}\text { Hymenaea courbaril var.stilbocarpa } \\
\text { (Hayne) }\end{array}$ & Caesalpiniaceae & 4 \\
\hline Hymenaea Stilbocarpa Hayne. & Fabaceae & 1 \\
\hline Joanesia princeps Vell. & Euphorbiaceae & 5 \\
\hline Tabebuia roseo-alba (Ridl.) Sandwith & Bignoniaceae & 3 \\
\hline Annona sp. & Annonaceae & 1 \\
\hline Platymenia foliolosa Benth. & Mimosaceae & 5 \\
\hline Platypodium elegans Vogel. & Fabaceae & 12 \\
\hline Psidium guajava L. & Myrtaceae & 1 \\
\hline Sapindus saponaria L. & Sapindaceae & 6 \\
\hline Spathodea nilótica Seem & Bignoniaceae & 1 \\
\hline Tabebuia ochraceae (Cham.) Standl. & Bignoniaceae & 1 \\
\hline Tabebuia sp. & Bignoniaceae & 5 \\
\hline Terminalia spp. & Combretaceae & 43 \\
\hline Trema micantra (L.) Blume & Cannabaceae & 4 \\
\hline Licania tomentosa (Benth.) Fritsch & Chrysobalanaceae & 499 \\
\hline
\end{tabular}


Syzygium cumini (L.) Skeels

Citrus sinensis (L.) Osbeck

Areca lutescens

Tibouchina granulosa (Desr.) Cogn.

Mangifera indica L.

Persea americana Mill.

Ligustrum lucidum W.T. Aiton

Jacaranda mimosaefolia D. Don

Centrolobium tomentosum Guillemin ex

Benth.

Murraya paniculata (L.) Jacq.

Citrus limonium

Bowdichia nitida Spruce ex Benth.

Não identificado

$\begin{array}{cc}\text { Myrtaceae } & 2 \\ \text { Rutaceae } & 5 \\ \text { Arecaceae } & 41 \\ \text { Melastomataceae } & 2 \\ \text { Anacardiaceae } & 2 \\ \text { Lauraceae } & 2 \\ \text { Oleaceae } & 2 \\ \text { Bignoniaceae } & 1 \\ \text { Fabaceae } & \\ \text { Rutaceae } & 1 \\ \text { Rutaceae } & 14 \\ \text { Fabaceae } & 2 \\ & 1 \\ & 4\end{array}$

Foram identificadas 41 espécies e uma morfoespécie, sendo que 4 indivíduos não foram identificadas pelo nome científico.

$\mathrm{Na}$ arborização urbana, segundo Silva (2000), é comum que poucas espécies representem a maior parte da arborização, como ocorrido em São João Evangelista. Mesmo não sendo uma situação desejável, alguns trabalhos também identificaram uma maior concentração de indivíduos de poucas espécies, dentre eles na cidade de Jacareí, estado de São Paulo (FARIA; MONTEIRO; FISCH, 2007).

De acordo com Araújo et al. (2009), procura-se desse modo, evitar problemas graves decorrentes de ataques de pragas e doenças que possam levar à perdas consideráveis em locais onde a diversidade é pequena.

A Tabela 3 apresenta as cinco espécies mais frequentes no município de São João Evangelista:

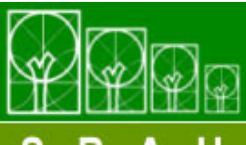

S $\cdot \mathbf{B} \cdot \mathbf{A} \cdot \mathbf{U}$ Soc. Bras. de Arborização Urbana 
Tabela 3. Cinco espécies mais frequentes no município de São João Evangelista-MG Table 3. Five most common species in the city of São João Evangelista-MG

\begin{tabular}{lcc}
\hline \multicolumn{1}{c}{ Espécie } & No de indivíduos & $\%$ \\
\hline Licania tomentosa (Benth.) & 499 & 61,30 \\
Ficus spp. & 45 & 5,52 \\
Terminalia spp. & 43 & 5,28 \\
Areca lutescens & 41 & 5,03 \\
Caesalpinia peltophoroides & 33 & 4,05 \\
\hline
\end{tabular}

Em um total de 814 árvores recenseados, constatou-se que o maior número de árvores encontradas foi da espécie exótica Licania tomentosa, $n=499$, seguido do gênero Ficus spp., $\mathrm{n}=49$, Terminalia spp., $\mathrm{n}=43$, Areca lutescens, $\mathrm{n}=41$ (palmeira) e Caesalpinia peltophoroides, $n=33$. Resultado semelhante foi encontrado na cidade de Uberlândia-MG, por Silva et al. (2002), onde foram identificados 1329 indivíduos de 30 espécies, sendo a Licania tomentosa com 430 indivíduos (32\%), e a segunda árvore mais abundante a Ficus benjamina com 205 indivíduos (15\%). Já estudos de Ibiapina et al. (2007) em Teresina-PI, mostraram que a Licania tomentosa foi a espécie mais representativa com $61 \%$ dos 105 indivíduos amostrados.

Houve grande diferença quanto à ocorrência de árvores entre as diferentes ruas do município, sendo a Avenida $1^{\circ}$ de Junho a que obteve a maior quantidade de indivíduos amostrados, $\mathrm{n}=193$ (sendo destes 93 indivíduos da espécie Licania tomentosa), seguido pela Rua Cônego Davino, com 67 indivíduos (66 indivíduos da espécie Licania tomentosa e 1 indivíduo da espécie Bauhinia variegata).

Segundo Silva et al. (2008), o recomendado é que cada rua tenha uma determinada espécie, outros autores sugerem que pelo menos cada quadra tenha apenas uma mesma espécie, e ainda sugerem que podem ser colocadas espécies diferentes, contudo em cada lado da rua deve prevalecer a mesma.

As ruas com menor frequência de árvores foram Benjamim Guedes e Rua Coluna, com 1 e 3 indivíduos respectivamente, ambas com representantes apenas da espécie Licania tomentosa.

A praça melhor arborizada foi a Praça Coronel Cornélio Pimenta com 53 indivíduos, sendo 32 representantes da espécie Licania tomentosa e 13 representantes da Areca lutescens.

Alguns autores, dentre eles Milano e Dalcin (2000), afirmam que cada espécie não deve ultrapassar $15 \%$ do total de indivíduos da população arbórea, para um bom (1) (P)

$\mathbf{S} \cdot \mathbf{B} \cdot \mathbf{A} \cdot \mathbf{U}$ Soc. Bras. de Arborização Urbana 
planejamento da arborização. Dentro desse aspecto, a espécie Licania tomentosa, foi a espécie predominante que apresentou $61,30 \%$ do total de indivíduos da população, extrapolando as recomendações desses autores.

A tabela 4 apresenta os resultados obtidos em relação a todas as variáveis analisadas, indicando as porcentagens para cada classe:

Tabela 4. Resultados obtidos para as variáveis analisadas no Inventário Arbóreo do município de São João Evangelista-MG

Table 4. Results for the analized variables in the Inventory of the city of São João Evangelista-MG

\begin{tabular}{|c|c|c|c|c|}
\hline \multirow{2}{*}{ Variável } & \multicolumn{4}{|c|}{ Classe } \\
\hline & 0 & 1 & 2 & 3 \\
\hline Altura total & $36,24 \%(n=296)$ & $40,66 \%(n=331)$ & $22,23 \%(n=163)$ & $0,85 \%(n=24)$ \\
\hline $\begin{array}{l}\text { Altura de primeira } \\
\text { bifurcação }\end{array}$ & $43,48 \%(n=354)$ & $21,49 \%(n=175)$ & $25,55 \%(n=208)$ & $9,45 \%(n=77)$ \\
\hline Diâmetro de copa & $32,80 \%(n=267)$ & $38,94 \%(n=317)$ & $21,99 \%(n=179)$ & $4,05 \%(n=33)$ \\
\hline Fitossanidade & $4,29 \%(n=35)$ & $10,56 \%(n=86)$ & $32,80 \%(n=267)$ & $52,33 \%(n=426)$ \\
\hline Largura do passeio & $28,37 \%(n=231)$ & $9,58 \%(n=78)$ & $55,15 \%(n=449)$ & $6,87 \%(n=56)$ \\
\hline Problema de raiz & $61,18 \%(n=498)$ & $22,60 \%(n=184)$ & $13,63 \%(n=111)$ & $2,58 \%(n=21)$ \\
\hline Conflito com fiação & $68,30 \%(n=556)$ & $7,70 \%(n=63)$ & $18,00 \%(n=147)$ & $6,00 \%(n=48)$ \\
\hline $\begin{array}{l}\text { Circunferência de } \\
\text { ocupação }\end{array}$ & $4,79 \%(n=39)$ & $9,95 \%(n=81)$ & $17,69 \%(n=144)$ & $67,56 \%(n=550)$ \\
\hline Idade & $1,59 \%(n=13)$ & $4,05 \%(n=83)$ & $38,32 \%(n=312)$ & $49,87 \%(n=406)$ \\
\hline
\end{tabular}

Em geral, as árvores do município analisado, com referência à altura total, estão concentradas na classe $0(<5 \mathrm{~m})$ representada por 296 indivíduos, e na classe $1(5,1$ a 10m) com 331 indivíduos, possuindo apenas 24 indivíduos na classe $3(>15 \mathrm{~m})$ sendo destes 7 indivíduos da Licania tomentosa e 7 indivíduos da espécie Areca lutescens.

Para a inserção da primeira bifurcação, 77 indivíduos possuem bifurcação superior a 2,00m (classe3) e 354 indivíduos apresentaram bifurcação inferior a 1,00m (classe 0). Tal

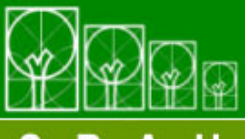

$\mathbf{S} \cdot \mathbf{B} \cdot \mathbf{A} \cdot \mathbf{U}$ Soc. Bras. de Arborização Urbana

REVSBAU, Piracicaba - SP, v.6, n.4, p.158-174, 2011 
resultado sugere que seja feita uma melhor condução das árvores urbanas, principalmente nas que se encontram na fase inicial de desenvolvimento, com poda de direcionamento, evitando problemas futuros para o trânsito de pedestres.

O correto é realizar a condução da árvore desde jovem, quando tem maior capacidade de cicatrização e regeneração para que esta tenha um crescimento adequado ao local de plantio.

A poda, na arborização urbana, visa basicamente conferir à árvore uma forma adequada durante o seu desenvolvimento. A poda de formação é empregada, de acordo com Marto et al.,(2006) para substituir os mecanismos naturais que inibem as brotações laterais e para conferir à árvore crescimento ereto, e à copa altura que permita o livre trânsito de pedestres de veículos.

Para a variável diâmetro da copa, constatou-se que 2,21\% indivíduos estavam isentos de copa $(n=18), 32,80 \%(n=267)$ dos indivíduos possuíam copa inferior a $4 m$ (classe 0), 38,94\% ( $n=317)$ possuíam copa entre 4,1 e $7 m$ (classe 1), 21,99\% ( $n=179)$ pertencem à classe 2, e a classe 3 apresentava 33 indivíduos (4,05\%) com diâmetro de copa superior a $10 \mathrm{~m}$.

Em trabalho realizado em dois bairros de Nova Iguaçu- RJ, Rocha; Leles e Neto (2004) verificaram que a maioria das árvores apresentavam diâmetro de copa entre 0 (zero) e 2,50m, associando os resultados a podas motivadas por conflitos com a rede elétrica, postes de iluminação, pontos de ônibus e construções.

Ao analisar a fitossanidade dos indivíduos inventariados, foram registrados $52,33 \%$ dos indivíduos ( $n=426)$ apresentando boa fitossanidade, 32,80\% ( $n=267)$ com fitossanidade regular, 10,5\% com fitossanidade ruim $(n=86)$ e 4,29\% dos indivíduos classificados como mortos $(n=35)$, sendo destes 26 indivíduos pertencentes a espécie Licania tomentosa, e 6 indivíduos da espécie Terminalia spp.

Em relação às calçadas, observou-se que 231 indivíduos se encontravam em local desprovido de passeio (classe 0), e que 449 indivíduos se encontravam em calçadas de 1,6 a 3,0m (classe 2).

Segundo CEMIG (2001), passeios com dimensões superiores a 2,0m são considerados largos, desta forma observou-se que 123 indivíduos estavam na classe 2, em passeios entre 1,6 a 3,0m, e 23 indivíduos em passeio com largura superior a 3,0m. Das 548 árvores encontradas na classe superior a $45 \mathrm{~cm}$ de circunferência, apenas 43 indivíduos se encontravam em calçada com largura superior a $3 \mathrm{~m}$.

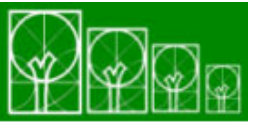

$\mathbf{S} \cdot \mathbf{B} \cdot \mathbf{A} \cdot \mathbf{U}$ Soc. Bras. de Arborização Urbana

REVSBAU, Piracicaba - SP, v.6, n.4, p.158-174, 2011 
De acordo com o Manual Técnico de Arborização Urbana da Secretaria do Verde e do Meio Ambiente (2005) da Prefeitura da cidade de São Paulo, para passeios públicos medindo de 2,0 a 2,40m de largura, é recomendado o plantio de espécies de médio porte (até $8 \mathrm{~m}$ de altura), e passeios maiores que $3 \mathrm{~m}$ comportam espécies de grande porte (maiores que $12 \mathrm{~m}$ de altura).

$\mathrm{Na}$ escolha das espécies, deve-se estar atento ao tipo de sistema radicular das árvores, pois as raízes devem ser profundas, para que não prejudiquem o calçamento e os dutos da rede subterrânea. Este parâmetro, devido sua importância, figura em quase todos os tipos de inventários de árvores urbanas. Ele diz respeito à presença e às condições do sistema radicular de espécimes que apresentam raízes superficiais, causando danos ou não. Essa informação é de grande importância, visto que a existência de danos deve ser corrigida. É útil também para se verificar casos especiais como o de plantas que têm como características apresentar sistema radicular profundo, mas, devido ao local onde foram plantadas podem apresentar raízes superficiais causando danos ao piso (SILVA; PAIVA; GONÇALVES, 2007).

Com relação à interferência das raízes nas calçadas, observou-se que apenas 2,58\% dos indivíduos encontrados destroem o passeio com as raízes (classe 3), o que equivale a apenas $6,67 \%$ do número de espécies encontradas, ou seja, apenas três espécies: Ficus spp, Licania tomentosa e Terminalia spp.

Dos 814 indivíduos 61,18\% ( $\mathrm{n}=498)$ não apresentam problemas na calçada. Resultado semelhante foi encontrado por Minhoto; Monteiro e Fisch (2009) na cidade de Taubaté-SP, no centro comercial histórico e em um bairro residencial moderno onde $66,89 \%$ dos indivíduos apresentavam raízes subterrâneas, que não estavam danificando as calçadas.

De modo a evitar danos causados pelo sistema radicular das árvores, os planos de arborização das cidades devem respeitar a área livre mínima de 1,00 $\mathrm{m}^{2}$, inclusive para que possam ser realizadas a irrigação e adubação periódica (COELBA, 2002).

Circunferência de ocupação das árvores é um parâmetro importante para conhecimento do porte da árvore para se ter uma idéia razoável da idade da mesma (jovem/adulta). Assim, além das estimativas de desenvolvimento, o que mais importa na medição de diâmetro é saber o espaço que ele ocupa em disputa com o pedestre.

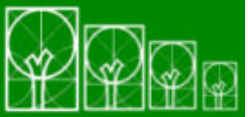

$\mathbf{S} \cdot \mathbf{B} \cdot \mathbf{A} \cdot \mathbf{U}$ Soc. Bras. de Arborização Urbana

REVSBAU, Piracicaba - SP, v.6, n.4, p.158-174, 2011 
A circunferência de ocupação das árvores maior que $45,0 \mathrm{~cm}$ (classe 3) é representada por $67,56 \%$ dos indivíduos $(n=550)$, o que demonstra uma arborização composta maciçamente por árvores adultas.

Dos indivíduos que se encontram em calçadas, 68,18\% estão locados onde não há fiação $(n=555)$. Valores próximos a este foram encontrados por Minhoto; Monteiro e Fisch (2009), na cidade de Taubaté-SP, onde $56,87 \%$ dos indivíduos não estavam plantados sob a rede.

Dos 814 indivíduos, 7,73\% ( $\mathrm{n}=63)$ apresentavam suas copas acima da fiação, 18\% ( $n=147)$ apresentavam a fiação atravessando o meio da copa, e 6,01\% ( $n=49)$ possuíam a fiação passando por cima da copa. As espécies que apresentaram maior incompatibilidade com a rede elétrica foram Licania tomentosa, Terminalia spp., Ficus spp., e Caesalpinia peltophoroides.

Os fios de alta tensão variam entre 9 e 12m de altura (CEMIG, 2001), assim, a maioria das espécies não apresentou conflito com a fiação, entretanto era comum observar que algumas espécies sofreram podas drásticas.

Em relação ao Quociente de Mistura de Jentsch (QM), que representa o número de indivíduos amostrados em relação às espécies encontradas no povoamento, obteve-se $\mathrm{QM}=$ 0,05159. Segundo Souza e Almeida (1997) citado por Scolforo e Melo (2006), quanto maior a mistura, ou seja, menor denominador, maior será a diversidade, podendo assim realizar comparações entre povoamentos arbóreos urbanísticos.

Desta forma, considerando que, segundo Milano e Dalcin (2000), para compor a arborização de uma cidade, deve-se utilizar entre 10 e 20 diferentes espécies, as vias públicas analisadas no município de São João Evangelista estão indicando uma boa distribuição das espécies (45 espécies identificadas e uma espécie não identificada), embora $81,18 \%$ dos indivíduos se concentrem em apenas cinco das espécies encontradas.

\section{CONCLUSÕES}

Com base no levantamento realizado no município de São João Evangelista, e na análise dos resultados obtidos, pode-se observar que as 42 espécies levantadas indicam uma elevada diversidade na arborização do município como um todo. Porém, para todas as

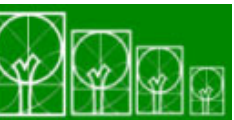

$\mathbf{S} \cdot \mathbf{B} \cdot \mathbf{A} \cdot \mathbf{U}$ Soc. Bras. de Arborização Urbana 
ruas houve distribuição desigual dessas espécies, com a prevalência de uma única espécie: Licania tomentosa.

A principal Avenida de São João Evangelista, melhor arborizada em termos quantitativos não apresenta uma identidade própria do bioma local com relação ao paisagismo, já que a espécie mais abundante (Licania tomentosa 61,30\%) é exótica da região. Sendo assim, se fazem necessários o estudo e a divulgação de espécies nativas com potencial de arborização para o município amostrado.

A inserção da primeira bifurcação para a maioria dos indivíduos recenseados demonstrou manejo inadequado.

Em relação aos conflitos com a rede elétrica, a maioria das árvores não apresenta incompatibilidade com a rede de energia.

A destruição das calçadas se deu pela implantação de espécies inadequadas, principalmente em relação ao porte.

Sugere-se:

- A substituição gradativa das árvores que entrarem em declínio, por espécies de menor porte e preferencialmente nativas da região.

- Nas áreas onde as calçadas são estreitas, a escolha da espécie arbórea a ser implantada, deve limitar-se a espécies de pequeno porte que não interfiram no trânsito de pedestres e não causem conflito com a rede elétrica.

- Que o manejo seja realizado por equipes aptas e treinadas, principalmente nos casos de conflito com a rede elétrica, e realizada uma melhor condução das árvores urbanas, principalmente nas que se encontram na fase inicial de desenvolvimento com poda de direcionamento.

\section{REFERÊNCIAS BIBLIOGRÁFICAS}

ADRIANO, J. R.; WERNECK, G. A. F.; SANTOS, M. A.; SOUZA, R. C. A construção de cidades saudáveis: uma estratégia viável para a melhoria da qualidade de vida? Ciência e Saúde Coletiva, v. 5, n. 1, p. 53-62, 2000. 
ARAÚJO, A. C.; RIBEIRO, I. A. M.; MORAIS, M. S.; ARAÚJO, J. L. O. Análise qualiquantitativa da arborização no bairro presidente Médici, Campina Grande-PB. REVSBAU. Piracicaba, v. 4, n. 1, p.133-144, 2009.

BUSS, P. M. Promoção da saúde e qualidade de vida. Ciência e Saúde Coletiva, v. 5, n. 1, p.163-177, 2000.

CEMIG - COMPANHIA ENERGÉTICA DE MINAS GERAIS. Manual de arborização. Belo Horizonte: Superintendência do Meio Ambiente/CEMIG, 2001. 40 P.

COELBA - COMPANHIA DE ELETRICIDADE DO ESTADO DA BAHIA. Guia de arborização urbana. Salvador: Venturie Gráfica e Editora, 2002, 55 p.

FARIA, J. L. G.; MONTEIRO, E. A.; FISCH, S. T. V. Arborização de vias públicas do município de Jacareí-SP. REVSBAU. Piracicaba, v. 2, n. 4, dez. 2007, p. 20-33.

GONÇALVES, E. O.; PAIVA, H. N.,GONÇALVES, W.; JACOVINE L. A. G. Avaliação qualitativa de mudas destinadas a arborização urbana no Estado de Minas Gerais. Revista Árvore. Viçosa, v.28, n.4, julho/agosto, 2004.

IBGE. CENSO 2005. São João Evangelista: IBGE. Disponível em: <http://www.censo2005.ibge.gov.br/>. Acesso em: out. 2010.

IBGE. CENSO 2010. São João Evangelista: IBGE. Disponível em: <http://www.censo2010.ibge.gov.br/>. Acesso em: out. 2010.

IBGE. Sinopse do Censo Demográfico 2010. Instituto Brasileiro de Geografia e Estatística, Rio de Janeiro, 2011.

IBIAPINA, J. S.; SILVA, E. A.; CARVALHO, A. K. S.; BRITO, J. S. Análise quali-quantitativa da arborização da Avenida Santos Dumont, zona norte, Teresina-PI. In: II Congresso de Pesquisa e Inovação da Rede Norte Nordeste de Educação Tecnológica. João Pessoa, 2007.

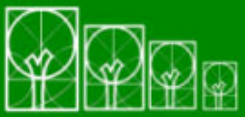

$\mathbf{S} \cdot \mathbf{B} \cdot \mathbf{A} \cdot \mathbf{U}$ Soc. Bras. de Arborização Urbana 
MARTO, G. B. T.; BARRICHELO, L. E. G.; SILVA, D. F.; MULLER, P. H. Arborização urbana. IPEF, Piracicaba, $2006 . \quad$ Disponível em: <http://www.ipef.br/silvicultura/arborizacaourbana.asp>. Acesso em: mar. 2009.

MENESES, C. H. S. G; SOUSA, E. B. M.; MEDEIROS, F. P. M.; MENEZES, I. R.; ALBUQUERQUE, H. N.; SANTOS, L. Análise da arborização dos bairros do Mirante e Vila Cabral na cidade de Campina Grande-PB. Revista de Biologia e Ciências da Terra, Campina Grande, v.3, n.2., 2003.

MICROSOFT EXCEL. Microsoft Corporation. Versão 7. 2000.

MILANO, M S. O Planejamento da arborização, as necessidades de manejo e tratamentos culturais das árvores de ruas de Curitiba-PR. Revista do Centro de Pesquisas Florestais. vol. XVII. n¹, 1987, p.15-21.

MILANO, M. S. Métodos de amostragem para avaliação de ruas. In: Congresso Brasileiro sobre Arborização Urbana, 2, São Luiz, 1994. Anais... São Luiz: SBAU, 1994. p.163-168.

MILANO, M. S.; DALCIN, E. Arborização de vias públicas. Rio de Janeiro: Light, 2000. 206p.

MINHOTO, E. S.; MONTEIRO, E. A.; FISCH, S. T. V. Arborização viária na cidade de Taubaté-SP: no centro comercial histórico e um bairro residencial moderno. REVSBAU, Piracicaba, v.4, n.2, p.82-96, 2009.

OLIVEIRA, F. A. C. et al. Inventário da arborização do campus Pato Branco da Universidade Tecnológica Federal do Paraná - UTFPR. REVSBAU, Piracicaba, v.4, n.1, p. 93-106, 2009.

PNUD. IDH 2000. São João Evangelista: PNUD. Disponível em: <http://www.pnud.org.br>. Acesso em: out. 2010.

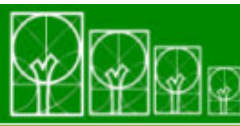

S · B · A $\cdot$ U Soc. Bras. de Arborização Urbana 
ROCHA, R. T.: LELES, P. S. S.: NETO, S. N. O. Arborização de vias públicas em Nova Iguaçu, RJ: o caso dos bairros Rancho Novo e Centro. Revista Árvore, Viçosa, v.28, n.4, p. 599-607, 2004.

SANTOS, F. C. O manejo da floresta urbana direcionada à convivência harmônica com as redes de distribuição: um estudo de caso na cidade de Gurinhatã, MG. Comisión de Integración Energética Regional. Belo Horizonte, 2008.

SANTOS, N. R.Z.; TEIXEIRA, I. F. Arborização de vias públicas: ambiente $\mathbf{X}$ vegetação. Santa Cruz do Sul: Instituto Souza Cruz, 2001.

SCOLFORO, J. R. S.; MELO, J. M. Inventário Florestal. UFLA- FAEPE. Lavras, 2006.

SECRETARIA DO VERDE E DO MEIO AMBIENTE. Manual técnico de arborização urbana. São Paulo, 2ed. 2005.

SILVA, A. G.; PAIVA, H. N.; GONÇALVES, W. Avaliando a arborização urbana. Viçosa: Aprenda Fácil. 2007.

SILVA, A. G. Arborização urbana em cidades de pequeno porte: avaliação quantitativa e qualitativa. 2000. 150f. Dissertação (Mestrado em Ciências Florestais)- Universidade Federal de Viçosa, Viçosa, 2000.

SILVA, E. M.; SILVA, A. M.; MELO, P. H.; BORGES, S. S.;LIMA, S. C. Estudo da arborização urbana do bairro Mansour, na cidade de Uberlândia-MG. IG/UFU. Caminhos de Geografia-Revista on line. v. 3, n.5, p. 73-83, fev. 2002.

SILVA, L. M.; CADORIN, D. A.; OLIVEIRA, K. A.; OLIVEIRA, F. A. C.; BETT, C. F. Inventário da arborização em duas vias de Mariópolis - PR. REVSBAU. Piracicaba, v.3, n.1, mar. 2008, p. 36-53.

SOARES, C. P. B.; NETO, F. P.; SOUZA. A. L. Dendrometria e Inventário Florestal. Viçosa-MG. Editora UFV, 2007, p. 276.

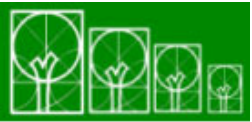

$\mathbf{S} \cdot \mathbf{B} \cdot \mathbf{A} \cdot \mathbf{U}$ Soc. Bras. de Arborização Urbana 